\title{
Violencia Política y Movilización Popular: Chihuahua (México), 1972*
}

\begin{abstract}
Gerardo Necoechea Gracia
Profesor titular de la cátedra de Historia Social de México siglo XX y en el Posgrado en Historia y Etnohistoria, de la Escuela Nacional de Antropología e Historia (México). Es, también, investigador adscrito a la Dirección de Estudios Históricos, del Instituto Nacional de Antropología e Historia (DEH-INAH). Correo electrónico: gnecoechea@yahoo.com. El autor es Doctor en Historia por la University City of New York y por la Escuela Nacional de Antropología e Historia Forma parte de la Asociación Mexicana de Historia Oral. Entre sus publicaciones recientes tenemos: "De enfermedades, historias y lecturas: imágenes narrativas de cultura obrera." Revista Territórios e Fronteiras Vol. 12 No. 1 (2019) y "La prensa de izquierda en México en la década de 1970: El ¿Qué Hacer? y la fundación de El Martillo” Cuicuilco Vol. 25 No. 71 (2018). Entre sus temas de interés están la historia cultural de la clase obrera y las culturas políticas de la izquierda.
\end{abstract}

\section{Alicia De Los Ríos Merino}

Es docente e investigadora de tiempo completo en la Facultad de Filosofía y Letras de la Universidad Autónoma de Chihuahua (México). Correo electrónico: adelosrios@uach.mx. La autora es maestra en Historia por la Escuela Nacional de Antropología e Historia (México) y candidata a doctora en Historia por la misma institución. Forma parte del Grupo de Trabajo CLACSDO Izquierdas: praxis y transformación social; de la Red de Historia del Tiempo Presente; de la Asociación Mexicana de Historia Oral; del Colectivo Epistémico de Teoría Crítica de Chihuahua (COLEPI) y de la Red Chihuahuense de Historia Oral. Entre sus publicaciones recientes tenemos: "La Huelga de 1967 en la Escuela Superior de Agricultura Hermanos Escobar", Chibuabua Hoy Vol.14 (2016) y "Habitar la memoria en Latinoamérica. De contar la historia a encender el fuego nuevo", Revista Pacarina del Sur No. 28 (2016). Entre sus temas de interés están XXX

Recibido: 17 de enero de 2020

Aprobado: 24 de abril de 2020

Modificado: 7 de mayo de 2020

Artículo de investigación científica

DOI: https://doi.org/10.15648/hc.39.2021.2962

Este artículo forma parte del proyecto "Cultura, izquierda política y trabajadores en México: 19501990” financiado por el Instituto Nacional de Antropología e Historia (México).

Esta publicación está bajo una licencia Creative Commons Reconocimiento-NoComercial 4.0 (cc) BY-NC 


\title{
Violencia Política y Movilización Popular: Chihuahua (México), 1972
}

\section{Resumen}

El presente artículo trata del surgimiento del Comité de Defensa Popular, en Chihuahua en el año de 1972. El ensayo propone que este Comité surgió debido a la convergencia de luchas sociales que venían ocurriendo durante la década de 1960, de manera separada. La convergencia ocurrió, primero, debido a la acción de un grupo político-militar y la represión que siguió; y segundo, debido a las redes de relación que se habían tejido entre quienes participaron en las distintas luchas sociales. El artículo, por esa razón, describe la trayectoria de los grupos armados y de los movimientos estudiantil, urbano popular y sindical: el CDP fue punto de llegada para todos ellos. La protesta social posterior evidenció un cambio cualitativo, debido a la unión de fuerzas y coordinación de acciones.

Palabras clave: Comité de Defensa Popular de Chihuahua, movimientos sociales, Partido Comunista Mexicano, Movimiento Sindical Ferrocarrilero, Organizaciones político-militares, Colonia Pancho Villa.

\section{Political Violence and Popular Mobilization: Chihuahua, 1972}

\begin{abstract}
This article discusses the People's Defense Committee (CDP), organized in the city of Chihuahua (Mexico) in 1972. The Committee, we argue here, emerged as the result of a convergence process of social struggles taking place separately through the 1960s. Such convergence occurred, first, due to the action of a political-military group and the repression that followed; and second, due to the networks of relationships that had been emerged among those involved in the various social struggles. For this reason, this article describes the path of the armed groups and the student, urban popular and union movements in Chihuahua: the CDP was a common point of arrival. The subsequent social protest was qualitatively different because of the strength gained by unified and concerted actions.
\end{abstract}

118 Key words: People's Defense Committee of Chihuahua, social movements, Mexican Communist Party, Movimiento Sindical Ferrocarrilero, armed-political organizations, Colonia Pancho Villa. 


\section{Violência Política e Mobilização Popular: Chihuahua, 1972}

\section{Resumo}

O presente artigo trata do surgimento do Comitê de Defesa Popular na cidade de Chihuahua no ano de 1972. O texto propõe que este Comitê surgiu devido à convergência de diferentes lutas sociais que vinham ocorrendo ao longo da década de 1960. Esta convergência aconteceu, primeiro, devido à ação de um grupo político-militar e da repressão desencadeada contra ele, e, segundo, graças às redes de relação que haviam sido tecidas entre aqueles que participaram nas distintas lutas sociais. O artigo, por esta razão, descreve a trajetória dos grupos armados e dos movimentos estudantil, urbano popular e sindical: o CDP foi o campo de chegada para todos eles. O protesto social posterior evidenciou uma transformação qualitativa como resultado da união das forças e da coordenação das ações.

Palavras-chave: Comitê de Defesa Popular de Chihuahua, movimentos sociais, Partido Comunista Mexicano, Movimento Sindical Ferroviário, organizações político-militares, colonia Pancho Villa.

\section{Violence Politique et Mobilisation Populaire: Chihuahua, 1972}

\section{Résumé}

Cet article traite de l'émergence du Comité de défense populaire, à Chihuahua en 1972. L'essai propose que ce Comité soit né en raison de la convergence des luttes sociales qui s'étaient produites tout au long des années 1960, séparément. La convergence s'est produite, d'abord, en raison de l'action d'un groupe politico-militaire et de la répression qui a suivi; et deuxièmement, en raison des réseaux de relations tissés entre ceux qui ont participé aux différentes luttes sociales. L'article, pour cette raison, décrit la trajectoire des groupes armés et des mouvements étudiants, populaires urbains et syndicaux: le CDP a été le point d'arrivée pour tous. La protestation sociale qui a suivi a mis en évidence un changement qualitatif, dû à l'union des forces et à la coordination des actions.

Mots clés: Comité de défense populaire de Chihuahua, mouvements sociaux, Parti communiste mexicain, Movimiento Sindical Ferrocarrilero, organisations politico-militaires, Colonia Pancho Villa. 


\section{INTRODUCCIÓN}

Los años que van de la huelga de los trabajadores ferrocarrileros en 1958-59 a la aprobación de la Ley de Organizaciones Políticas y Procedimientos Electorales en 1977, estuvieron marcados por represión y protesta. En el norteño estado de Chihuahua, durante estas dos décadas se sucedieron oleadas de luchas sociales. Iniciaron con tomas de tierra por campesinos cansados de esperar a que las leyes de reforma agraria finalmente se hicieran efectivas. Siguieron las protestas y huelgas de estudiantes en educación media y superior, persiguiendo demandas propias y ofreciendo apoyo a otros. La movilización campesina se entretejió con la de estudiantes normalistas y maestros rurales, y juntas trazaron la senda que condujo a la formación del Grupo Popular Guerrillero, considerado el inicio del movimiento armado socialista en México. Hacia el final de los sesenta, en la capital estatal, inmigrantes rurales en necesidad de habitación invadieron predios urbanos. Al inicio de la nueva década, el descontento puso a los trabajadores urbanos en la ruta de la protesta. En 1972, un asalto malogrado en la ciudad de Chihuahua fue el motivo para que estos distintos hilos de la protesta social se entretejieran en un tapiz que envolvería a la sociedad urbana. Algunos observadores consideraron entonces que Chihuahua era ejemplo de insurgencia obrera y popular'.

Las investigaciones históricas de estos años, o del periodo de la Guerra Fría en general, han aumentado en los últimos años. Sobresale el interés por la violencia política, y en particular, por los grupos políticos armados. Las obras que sobre el asunto se escribieron entre la década de 1970 y el inicio del nuevo siglo hicieron crónica periodística o acomodaron los sucesos para fortalecer sus argumentos en la polémica política contemporánea. Fue común entonces referirse a las organizaciones político-militares, habitualmente denominadas guerrilleras, de manera negativa, suponiendo que existían aisladas de los movimientos y luchas sociales y que sus integrantes eran, en el mejor de los casos, individuos desesperados, o en el peor de los casos, saboteadores de las

1 "El primero de mayo: fin de la unanimidad", Punto Crítico, Ciudad de México, mayo, 1972, 2 y $3^{\circ}$ de forros. 
luchas sociales ${ }^{2}$. Las memorias y los estudios analíticos, muchos de ellos académicos, empezaron a aparecer en los años noventa y crecieron en número en las dos últimas décadas. Gracias a estos nuevos trabajos, la visión denigratoria ya es poco común.

Los estudios tienden a centrarse en el estudio de alguna organización en particular, tratando de entender su ideología y su funcionamiento interno. Los autores relacionan, de manera general, las causas de su aparición con condiciones estructurales y autoritarismo político. En el caso de las guerrillas rurales, particularmente en Guerrero y Chihuahua, ha sido más frecuente extender el estudio de las causas a la transformación de las condiciones económicas específicas y a la agitación y luchas sociales generadas por esas transformaciones ${ }^{3}$. Lo mismo no se ha hecho para las guerrillas urbanas, de manera que permanece la idea de que fueron un fenómeno estudiantil ajeno y que impactó negativamente a las luchas populares. Esta manera de construir el campo de estudio, contraponiendo movilización popular a grupos armados, obedece más a las discusiones políticas de época que a la investigación sobre unos y otros ${ }^{4}$. Gracias al cúmulo de investigación acerca de organizaciones como el Movimiento de Acción Revolucionaria, la Liga Comunista 23 de Septiembre y otras, es posible ya no solo cuestionar esta interpretación simple, sino plantear nuevas preguntas.

El vacío historiográfico existente es una invitación abierta a estudiar la relación entre estas organizaciones y los movimientos y luchas contemporáneas en sus locaciones específicas. Por razones de conveniencia para su estudio, fragmentamos la experiencia, separando protestas y

2 Dos revisiones historiográficas coinciden en este punto: Adela Cedillo y Fernando Herrera Calderón, "Análisis de la producción historiográfica en torno a la llamada guerra sucia mexicana". En El estudio de las luchas revolucionarias en América Latina (1959-1996): Estado de la cuestión, editado por Martín López Ávalos et al. Zamora: El Colegio de Michoacán y Universidad de Santiago de Compostela, 2014, 9. Sergio Arturo Sánchez Parra, "La guerrilla en México: un intento de balance historiográfico", Clío, nueva época Vol. 6 No. 35 (2006): 123.

3 Cedillo contrapone el modelo explicativo al modelo denigratorio; véase, por ejemplo, José Santos Valdés, Madera. Razón de un martirologio (Durango: Universidad Juárez del Estado de Durango, 2011); Armando Bartra, Guerrero Bronco, Campesinos, ciudadanos y guerrilleros en la Costa Grande (Ciudad de México: Era, 2000); y Aleida García Aguirre, La revolución que llegaría (Ciudad de México: Edición de autora, 2015).

$4 \quad$ Véase, por ejemplo, Mario Huacuja y José Woldenberg, Estado y lucha política en el México actual (México: Ed. El Caballito, 1976). 
movimientos sociales de las organizaciones a que dieron origen, incluso las armadas. Sin embargo, lo que fue conveniencia temporal se convierte en estancos separados de especialización. Olvidamos, entonces, que la experiencia vivida por quienes atravesaron esos tiempos absorbió el todo, y fue en base a esa experiencia compleja que tomaron decisiones respecto de qué y cómo hacer. En otras palabras, es necesario abandonar los estrechos marcos políticos e institucionales y pasar a hacer una historia social de esos años.

Aquí nos centramos en un movimiento detonado por una acción guerrillera que adquirió carácter masivo, transformó cualitativamente las acciones de protesta e impactó la política local. El estudio centrado en un lugar y circunstancias específicas nos permite sugerir la convergencia de olas de movimientos sociales, iniciadas en distintos lugares y momentos, en la ciudad de Chihuahua en 1972. La creación del Comité de Defensa Popular al inicio de ese año fue un punto de llegada común y fue, así mismo, punto de partida cualitativamente distinto para la lucha social, incluyendo la llevada a cabo por organizaciones político- militares. Este artículo examina el primer momento, es decir, los procesos que desembocan en la fundación del Comité. El segundo momento está más allá de nuestra presente intención, y apenas queda sugerido a través de la descripción de acciones ocurridas inmediatamente después de fundado el CDP.

\section{El triple asalto}

A las 9:30 de la mañana del 15 de enero de 1972, cuatro jóvenes, dentro de un auto estacionado, vigilan la sucursal del Banco Comercial Mexicano. Una patrulla del ejército está estacionada cerca del edificio. Los jóvenes dudan. Avelina decide la jugada, aseverando que lo que se requiere es decisión firme. Ella y otros dos salen del auto, entran

122 al banco e informan a todos los presentes que vienen a realizar una expropiación. Otros dos grupos de jóvenes, en sendos otros bancos en la ciudad, hacen lo mismo más o menos a la misma hora. Inició así 
la Operación Madera, después mejor conocida como el triple asalto bancario ${ }^{5}$.

El grupo responsable por la planeación y ejecución era parte de la organización conocida como Los Guajiros. El dirigente que encabezó la acción en Chihuahua era Diego Lucero. Los tres comandos involucrados llevaban, cada uno, el nombre de un guerrillero chihuahuense muerto: Oscar González, Arturo Gámiz y Carlos Armendáriz. Después de los sucesos, la prensa bautizó al grupo "Los Comandos Armados de Chihuahua".

El comando que asaltó el Comercial Mexicano estaba compuesto por Avelina Gallegos, Pablo Martínez, Oscar Montes y Ramiro Díaz. Los tres primeros ingresaron al edificio redondo con paredes de cristal, ordenaron a los clientes y empleados tenderse en el suelo, y fueron obedecidos. Una detonación sonó en la calle, sonido de cristal quebrado y Oscar Montes cayó herido; más balazos y también Pablo fue herido. Probablemente agazapada, Avelina disparó e hirió al jefe militar que en ese momento entró, y en respuesta recibió un balazo en la frente que la mató instantáneamente. Por fuera del edificio, soldados; adentro se vivía el caos de la balacera. Una mujer que intentó ganar la salida, recibió un disparo mortal. Terminaron las detonaciones, y además de la mujer, quedaron dos guerrilleros muertos. Pablo, herido, fue apresado. Más tarde lo sería también Ramiro, quien pudo huir de la escena por encontrase en el automóvil. Los otros dos asaltos sucedieron sin incidentes, y los comandos expropiaron cerca de medio millón de pesos.

Inmediatamente se organizó una cacería por toda la ciudad para dar con los asaltantes y recuperar el dinero. Las autoridades locales ofrecieron $\$ 200$ mil por información que ayudara a la captura de los responsables. El más joven del grupo, Rosendo Muñoz Colomo, fue entregado por

5 La reconstrucción del asalto y los sucesos inmediatos posteriores está basada en Laura Castellanos, México armado, 1943-1981 (Ciudad de México: Era, 2007), 186-188, y varios reportajes aparecidos en Punto Crítico, revista editada en la Ciudad de México: "Crónica nacional: la violencia es sistemática," febrero, 1972, 4-11; “Chihuahua, la verdad sobre los asaltos," abril, 1972, 19-21; Luis González de Alba, "Chihuahua, entrevista a presos políticos", diciembre, 1972, 30-31. Los nombres son los usados en los artículos, que no necesariamente eran los nombres reales; versiones posteriores difieren en detalles, algunos de importancia. 
su abogado y obligado a declarar. La policía uso la información para apresar a Marco Rascón y Francisco Javier Pizarro, y recuperar parte del dinero. La misma noche del sábado fue detenido Diego Lucero.

El domingo por la noche, el periodista ultraconservador Agustín Barrios Gómez informó por televisión de la muerte de Lucero en un enfrentamiento con la policía. La emisión originada en la Ciudad de México fue cortada en Chihuahua. Ese mismo domingo, Marco Rascón fue trasladado de su celda a un cuarto, donde tuvo a Lucero frente a sí. El procurador lo presentó como Raúl Díaz. "Yo me quedé callado —declaró Rascón posteriormente- mirando a Diego, quien tampoco hablaba, y asombrado de que hubieran conocido su seudónimo”. Más tarde, el procurador informó a Rascón que había ocurrido una balacera y la policía había matado a un individuo que intentó entrar a "la casa del puerto de San Pedro”; el procurador no identificó al muerto. Al otro día el procurador le informó que el occiso era Raúl Díaz. Marco respondió: "las revoluciones se hacen con la barbarie de unos y el sacrificio de otros". Por toda respuesta, el procurador "se encogió de hombros y se fue" . Al mediodía siguiente, el procurador informó de la balacera, del muerto aún sin identificar, y ofreció la foto de Lucero a los medios para apresurar la identificación.

Otras dos muertes ocurrieron. El jueves 20 de enero amaneció muerto en su celda Ramiro Díaz Ávalos, estudiante de la vocacional 5 del Politécnico Nacional en la ciudad de México, chofer en el asalto al Comercial Mexicano. Las fotografías lo mostraban "atado, más que suspendido, a la reja de la celda" y sangrando por la boca. La declaración oficial adjudicó la muerte a "autoestrangulamiento". El 21 apareció muerto Gaspar, en realidad Juan Gilberto Flores Díaz, miembro de la Juventud Comunista de Mexicali, ciudad fronteriza en el estado de Baja California. Él había sido detenido junto con Héctor Lucero Martínez en una población cercana a la ciudad de Chihuahua. Fue sacado de los separos de la Policía Judicial y muerto en la población de General Trías, acorde a la explicación oficial, porque intentó fugarse después de indicar el lugar donde había enterrado parte del dinero. Héctor Lucero

6 Luis González de Alba, "Chihuahua, entrevista”, 30-31. 
fue identificado por su padre, quien temía corriera la misma suerte que Diego si permanecía como desconocido. Héctor Lucero después declaró a Punto Crítico que fue él quien señaló a la policía el lugar del entierro del dinero?

Las muertes, cuyas extrañas circunstancias apuntaban a una decisión de asesinato extrajudicial por parte de las fuerzas públicas, causaron indignación en la ciudad. Los primeros en movilizarse fueron los estudiantes. Las autoridades universitarias calificaron a los jóvenes revolucionarios como "delincuentes y engañados por quienes deseaban de manera fácil el patrimonio popular de los chihuahuenses" e hicieron un llamado a los padres de familia para vigilar a sus hijos. Los universitarios respondieron exigiendo entrevistarse con el gobernador Óscar Flores, y nombraron una comisión para seguir las investigaciones y responsabilizar de las muertes al procurador de justicia del estado, Antonio Quezada Fornelli, y al jefe de la policía, Ambrosio Gutiérrez $z^{8}$ La pronta respuesta demostraba "el grado de desarrollo político" de los estudiantes y de toda la población, porque "se indignaron por los asesinatos extrajudiciales" y cuando "los compañeros que estaban directamente relacionados" llamaron a la movilización, "respondimos inmediatamente y la sociedad respondió". A continuación, los presidentes de sociedades de alumnos de escuelas universitarias, del Instituto Tecnológico y la Normal del estado integraron el Comité Coordinador Estudiantil de Enseñanza Superior (CCEES $)^{10}$. "Toda la Universidad empezó a derivar hacia la izquierda, la Normal, los Tecnológicos, la lucha popular, los sindicatos que se adhirieron" 11 .

Reunidos estudiantes, colonos, obreros y campesinos el 19 de enero en la plaza de armas, decidieron constituirse como Asamblea Popular ${ }^{12}$. La Asamblea exigió que el gobernador destituyera de sus cargos al Procurador y al Jefe de la policía de la ciudad; demandaron, también, que los presos que habían sido trasladados a la capital del país fueran regre-

\footnotetext{
"Chihuahua, la verdad", 21.

"Categórica afirmación del Gobernador a estudiantes”, Norte, Chihuahua, 18 de enero, 1972, 1. Entrevista a Muñoz, José Manuel, Ciudad de México, 14 de diciembre, 2016 y 15 febrero, 2017. "Manifestación y mitin de los estudiantes hoy", Norte, Chihuahua, 9 de febrero, 1972, 1. Entrevista a García Chávez, Jaime, Chihuahua, 21 de agosto, 2013.

"Chihuahua, la verdad", 20-21.
} 
sados a la cárcel en la ciudad. Los funcionarios impugnados, arguyendo que lo hacían para no interferir, solicitaron licencia y el gobernador se las concedió. Al final de la investigación, ambos fueron exonerados y reinstalados en su puesto. Mientras tanto, la Asamblea nuevamente reunida el 9 de febrero, discutió y aprobó la propuesta de formar el Comité de Defensa Popular ${ }^{13}$.

Así lo explicó un trabajador:

"El Comité de Defensa Popular que se inició en Chihuahua, al ver que el pueblo necesita defensor, entonces puso a votación del pueblo chihuahuense, votamos porque se hiciera el Comité de Defensa, y allí vemos que va en un ambiente de toda la república mexicana, que tendrá que reconocer el gran trabajo histórico que Chihuahua ha hecho de sus hermanos y para sus hermanos: los pobres"14.

\section{Convergencias}

La triple expropiación a instituciones bancarias del quince de enero de 1972 en la ciudad de Chihuahua generó un movimiento social inmediato sin precedentes. Este estallido, al parecer espontáneo, fue en realidad el resultado de solidaridades y convergencias gestadas a través de un largo trayecto, y que las ejecuciones extrajudiciales trajeron a la superficie. La fundación del Comité de Defensa Popular fue un punto de llegada en este proceso: un frente cuya unidad, acorde a varios de sus dirigentes, descansaba en la igualdad de condición y en los acuerdos tomados desde las bases.

La trayectoria de los grupos armados en el estado ayuda a entender la respuesta masiva a la muerte de los asaltantes identificados como el Comando Armado de Chihuahua. Esta trayectoria se remonta a las luchas campesinas en décadas anteriores, y al intento del Grupo Popular

13 "Tarjetas informativas sobre los antecedentes y la constitución del Comité de Defensa Popular en el estado de Chihuahua, por la Dirección Federal de Seguridad” (17 febrero, 1972), en Archivos de la Represión (AR), Colección MIDAS 3, en adelante AR MIDAS 3, CDP: https://biblioteca.archivosdelarepresion.org/s/comverdad/item/36629\#?c $=\& \mathrm{~m}=\& \mathrm{~s}=\& \mathrm{cv}=,(17 / 12 / 2019)$.

14 Grupo de Trabajo Antropología y Política ENAH, "Informe Especial. Chihuahua 1972: Una experiencia de lucha popular,” Punto Crítico, Ciudad de México, agosto, 1972. 6-7. 
Guerrillero (GPG) por tomar el cuartel de Ciudad Madera, al noroeste de la ciudad capital de Chihuahua, en la Sierra Madre Occidental, el 23 de septiembre de $1965^{15}$.

La fundación del GPG fue precedida por el empleo de tácticas legales, incluso electorales, y de invasiones de tierras llevadas a cabo por miles de hombres y mujeres campesinas. En la década de 1950 inició un pujante movimiento de luchas agraristas en la región de Babícora, con la participación del magisterio y de los campesinos organizados en la Unión General de Obreros y Campesinos de México (UGOCM), adherida al Partido Popular (que añadió la palabra Socialista a su nombre en 1962, PPS). Al frente de estas movilizaciones figuraron tres hombres: el médico y profesor Pablo Gómez, el líder campesino Álvaro Ríos y el profesor rural Arturo Gámiz. A partir de 1962, se engarzaron las luchas de los estudiantes normalistas y de los maestros con las demandas campesinas. Ni las marchas e invasiones de tierra en puntos cardinales del estado, ni las tomas de edificios, plantones y entrevistas con el gobernador lograron que se afectaran latifundios forestales y ganaderos, que ocupaban tres millones setecientas mil hectáreas de las mejores tierras de riego y de pastizales propiedad de ciento cuarenta y cinco familias.

En 1963 tuvo lugar el Primer Encuentro de la Sierra Heraclio Bernal. Ahí, los precursores del GPG expusieron su frustración con los recursos legales para obtener tierras. Su nueva decisión fue armarse y separar su camino de la UGOCM y el PPS. Los años 1964 y 1965 fueron de preparación militar y trabajo político entre estudiantes y campesinos mestizos, rarámuris y pimas. El grupo armado respondió con violencia a las complicidades de caciques, judiciales y militares. Salomón Gaytán, miembro de la familia Gaytán Aguirre, y Gámiz eran entonces los principales dirigentes del Grupo Popular. En febrero de 1965 celebraron el Segundo Encuentro en el poblado de Las Nieves, Torreón de Cañas, Durango.

15 Aleida García Aguirre, La revolución; Beth Henson, Agrarian Revolt in the Sierra of Chihuahua, 1959-1965 (Tucson: Arizona State University, 2019); Jesús Vargas Valdés, Madera Rebelde. Movimiento armado y guerrilla 1959-1965 (Chihuahua: Nueva Vizcaya, 2015). 
El 23 de septiembre de ese año, después de una serie de acciones en territorio serrano, el GPG atacó el cuartel de Madera, una pequeña población enclavada en los latifundios cuya repartición demandaban los campesinos. Los rebeldes pretendían golpear moralmente al ejército y publicitar los motivos de su lucha a través de la radio; además, expropiarían el banco de la localidad. No lo lograron. Al mediodía, las autoridades exhibieron en la plataforma de un camión los cuerpos masacrados de los combatientes. La prensa chihuahuense anunció: "Exterminada la gavilla de Gámiz"16.

La derrota no fue absoluta, ya que en los primeros meses de 1967 empezó el reparto de latifundios. Aun así, el fracaso del ataque, la muerte de varios guerrilleros y el encarcelamiento de otros parecía clausurar la vía armada en México. Sucedió lo contrario. En los siguientes años, la paz rural era aparente, a pesar del empeño publicitario de autoridades civiles y militares por demostrar el fin de grupos insurgentes en las montañas chihuahuenses. En septiembre de 1968, los periódicos del estado de Chihuahua publicaron un boletín de prensa emitido por la Quinta Zona Militar, que anunciaba "el aniquilamiento de una gavilla de jóvenes que renunciaron a su brillante porvenir" ${ }^{17}$. Se referían al Grupo Guerrillero del Pueblo Arturo Gámiz (GGPAG), una de las dos organizaciones fundadas por sobrevivientes del asalto al cuartel de Madera.

El GGPAG era comandado por el estudiante Óscar González Eguiarte. Él y Juan Antonio Gaytán Aguirre, Guadalupe Scobell Gaytán, José Luis Guzmán Villa y Arturo Borboa Estrada fueron fusilados el 11 de septiembre de 1968, en Tesopaco, Sonora, después de una larga excursión desde la sierra tarahumara hasta esos valles. Carlos Armendáriz Ponce, el combatiente más joven, murió días antes cubriendo la retirada de sus compañeros. González Eguiarte había anotado en su diario que, a pesar de los antecedentes agraristas e insurgentes en la zona, la sierra chihuahuense seguía en manos de latifundistas ganaderos y forestales que actuaban al amparo de las autoridades. Para acabar con este grupo de jóvenes insurgentes, que a su paso incendiaron un aserradero en

16 El Heraldo, Chihuahua, 24 de septiembre, 1965, 1.

17 "Boletín de la guarnición de la plaza", El Fronterizo, Ciudad Juárez, 23 de septiembre, 1968. 
Tomóchic y derribaron una avioneta del ejército, se desplegaron siete mil militares.

En ese mismo año de 1968, estudiantes en la ciudad de México iniciaron una huelga en julio. La huelga pronto involucró a estudiantes de todo el país. Terminada la larga huelga nacional, muchos de los estudiantes continuaron experiencias de organización política. Algunos entre ellos se inclinaron hacia las organizaciones armadas surgidas de las rupturas en las izquierdas del Partido Comunista y de la Liga Espartaco ${ }^{18}$.

Fue el caso de los hermanos Gabriel y Miguel Domínguez Rodríguez. Ellos nacieron en Durango y su familia emigró a Ciudad Juárez, Chihuahua. Los hermanos mudaron su residencia a la Ciudad de México, para estudiar en el Instituto Politécnico Nacional, y después del 68 se unieron al Comando Lacandones; por lo menos cuatro de los seis hermanos Domínguez participaron en Lacandones, tanto en la ciudad de México como en Juárez. Otros grupos surgieron en 1969: los Macías, en Monterrey y otros puntos de Durango y Tamaulipas, los Guajiros o Grupo N en la Ciudad de México, y los Procesos en diversas ciudades de la frontera norte.

Estos grupos establecieron comunicación entre sí tiempo después, y en 1973 fundaron la Liga Comunista 23 de Septiembre, la mayor organización insurgente de la década de los setenta. La idea de una organización nacional fue planteada por dos personajes norteños: Diego Lucero Martínez y Raúl Ramos Zavala. El primero fue dirigente estudiantil en la Universidad Chihuahua (UCH, posteriormente Universidad Autónoma de Chihuahua, UACH) en 1967, y egresó como ingeniero civil. En 1970 vivía en la Ciudad de México, y ahí integró, junto con Leopoldo Ángulo Luken, el Grupo "N" o Guajiros. A continuación, buscaron trabar relación con otros colectivos y crear una coordinación nacional. Coincidieron en este propósito con el econo-

18 Carlos Salcedo García, "Grupo Lacandones”, en La Liga Comunista 23 de septiembre, cuatro décadas a debate: historia, memoria, testimonio y literatura, eds. Rodolfo Gamiño, et al. (Ciudad de México: UNAM, 2014), 183-184; para un acercamiento crítico a la bibliografía acerca del movimiento estudiantil, véase Héctor Jiménez Guzmán, El 68 y sus rutas de interpretación (Ciudad de México: Fondo de Cultura Económica, 2018). 
mista Raúl Ramos Zavala y un grupo de jóvenes militantes del norte que abandonaron la Juventud Comunista Mexicana. En el transcurso de 1971 fueron forjando acuerdos y realizaron acciones menores de propaganda y expropiaciones ${ }^{19}$.

Antes de terminar ese año acordaron dos expropiaciones en contra de las burguesías locales chihuahuense y nuevoleonesa. El 14 de enero de 1972 actuó en Monterrey el grupo Los Procesos, y un día después, los Guajiros irrumpieron en tres sucursales bancarias de la ciudad de Chihuahua. Las expropiaciones fueron acciones planeadas desde una incipiente coordinación regional de grupos que pretendían la organización nacional. El triple asalto en Chihuahua, dirigido por Diego Lucero Martínez, constituyó el "tercer intento en el estado contra la oligarquía”, concebido por sus protagonistas como continuidad de las experiencias insurgentes del Grupo Popular Guerrillero (GPG) en 1965 y el Grupo Popular Guerrillero Arturo Gámiz (GPGAG) en 1968²0.

La movilización estudiantil, que nutrió a organizaciones de izquierda, fue desenvolviéndose en paralelo. A raíz del intento contrarrevolucionario de invasión en Playa Girón, Cuba, en 1961, profesores de la Normal del Estado y la Sociedad Amigos de Cuba convocaron a un mitin de apoyo a la revolución cubana. Estudiantes de la Normal Rural de Salaices, la Normal del Estado, la Escuela de Artes y Oficios y la Preparatoria de la Universidad convergieron por primera vez en un acto de protesta ${ }^{21}$. Tres años después, en febrero de 1964, la Normal del Estado, el Internado de Señoritas de la Normal del Estado y la Secundaria Estatal No. 4 emprendieron el paro solidario con la huelga sostenida por los estudiantes de la Escuela de Artes y Oficios de Chihuahua. El comité de huelga incluía a los estudiantes normalistas Andrés de la O Ayala, Rodolfo Ramos Beltrán y Emma Becerra Gaytán, junto a María Trinidad Eribes del

19 Fritz Glockner, Los años heridos. La historia de la guerrilla en México 1968-1985 (Ciudad de México: Planeta, 2019), 163-168; Diego Lucero Estrada, Sueños guajiros: Diego Lucero y la guerrilla mexicana de los años 60 y 70 (Ciudad de México: Casa de las Palabras, 2012), 55-88; Mario Ramírez Salas, "La relación de la Liga Comunista 23 de Septiembre y el Partido de los Pobres en el estado de Guerrero en la década de los setenta", en Movimientos armados en México, siglo XX, coords. Verónica Oikión y Marta Eugenia García (Zamora: El Colegio de Michoacán, Ciesas, 2008), 529.

20 Víctor Orozco Orozco, Diez ensayos sobre Chihuahua (Ciudad de México: Doble Hélice Ediciones, 2003), 14-15.

21 Aleida García Aguirre, La revolución, 63. 
Internado y Salvador García, de la Secundaria ${ }^{22}$. En abril de ese mismo año, estudiantes normalistas encabezaron un tumulto protestando que el candidato presidencial, Gustavo Díaz Ordaz, no quería escuchar las demandas campesinas, y terminaron quemando el templete erigido para el acto de campaña. En agosto, para castigar el apoyo a las tomas de tierras y a las acciones del GPG, el gobierno estatal cerró los internados de la Escuela de Artes y Oficios y el de Señoritas, en la capital, y las Normales nocturnas de Chihuahua, Juárez, Ojinaga y Parral. La Normal del Estado y las escuelas involucradas se fueron a huelga, pero no ganaron la reapertura de las escuelas. El normalista Oscar Sandoval Salinas experimentó la represión y la frustración, posibles razones por las que dejó la escuela y se unió al GPG; fue uno de los muertos durante el ataque al cuartel de Madera ${ }^{23}$.

Los estudiantes de la Escuela de Agricultura Hermanos Escobar (ESAHE) de Ciudad Juárez estallaron en 1967 la que fue la más importante huelga estudiantil en el estado. Demandaban que el Gobierno federal se hiciera cargo de la escuela, porque no obstante que recibía subsidios gubernamentales, era privada, y que en adelante la educación fuera gratuita. En los volantes mimeografiados que entregaban a las afueras de la ESAHE se leía: "Compañeros: no permitamos ya que Escobar Hnos. y Cía., sigan incrementando sus fortunas a costa del sacrificio de nuestros padres". Añadían que lo que recibían en enseñanza no valía la mitad de lo que pagaban en colegiatura. Organizaron un comité de huelga, y eligieron presidente al tamaulipeco Eduardo Merrem, y secretario a Pablo Martell, originario de San Luis Potosí24.

Resistieron por meses, a pesar de los embates del municipio, la Secretaría de Agricultura y Ganadería (SAG) y destacados integrantes de la Sociedad Agronómica Mexicana (SAM), incluyendo los dueños de la ESAHE. Comisiones diversas viajaron a la Ciudad de México para pedir la intervención de la SAG, cuyo titular también era socio de la SAM.

22 "Memorándum sobre las escuelas que continúan en huelga en el estado de Chihuahua, por la Dirección Federal de Seguridad" (6 de febrero, 1964), AR, Colección MIDAS 6: https://biblioteca. archivosdelarepresion.org/s/comverdad/item?search=Antonio+Becerra+Gaytan, (17/12/2019).

23 Aleida García Aguirre, La revolución, 123-126.

24 "Están exigiendo que la ESA sea federalizada", El Fronterizo, Ciudad Juárez, 9 de mayo, 1967, 1. 
Delegaciones de estudiantes de diversas escuelas del país arribaron a la ciudad fronteriza para apoyar y denunciar las acciones de represión del municipio y la cerrazón de autoridades federales. La Escuela Nacional de Agricultura, en la capital del país, se declaró en huelga el 5 de junio, y el resto de las escuelas agropecuarias siguieron el ejemplo. La Federación Nacional de Estudiantes de Ciencias Agrícolas y Forestales (FNECAF), la Federación de Estudiantes Campesinos Socialistas de México (FECSM) y la Confederación Nacional de Estudiantes Democráticos (CNED) encabezaron posteriores movilizaciones. A principios de julio, todas las escuelas del Instituto Politécnico Nacional se unieron a la huelga. "No vimos la dimensión que tuvo", reflexionó Martell años después. "Fue un antecedente muy importante para diseñar la dirección del 68, porque el movimiento de solidaridad del nuestro fue encabezado por un Comité Coordinador Estudiantil que se gestó precisamente en la Escuela de Físico Matemático del Politécnico"25.

Finalmente, el 15 de julio, los estudiantes aceptaron el ofrecimiento de la Universidad de Chihuahua, de crear de inmediato la Escuela de Agronomía, con un aumento en el subsidio que la SAG le asignaba a la ESAHE. Con la reciente experiencia a cuestas, llegaron los agrónomos a la ciudad de Chihuahua y a la Universidad. Ellos se consideraban a sí "gente pesada en los movimientos estudiantiles", y gravitaron de manera natural hacia otros activistas:

"[Nos relacionamos con] los compañeros de Leyes dirigidos por los Nachos, donde destacaban García Chávez, Víctor Orozco, el profesor Luna, los Churriques [Enrique y José Luis] Pallares. En Zootecnia estaba Nacho González, Roberto Sepúlveda era de la Facultad de Ingeniería y Marco Rascón en la Escuela Preparatoria. Además, había mucha actividad y amistad con el grupo que fundó la colonia (Francisco) Villa"26.

No bien empezaba 1968, cuando los estudiantes de Agronomía nuevamente se fueron a huelga, exigiendo que la Secretaría de Agricultura

25 Alicia de los Ríos Merino, "La huelga de 1967 en la ESAHE”, Chihuahua Hoy, Vol. 14 (2016): 131 132; Jesús Vargas Valdés, La patria de la juventud (Chihuahua: Nueva Vizcaya, 2008), 92.

26 Alicia de los Ríos Merino, "Huelga de 1967”, 136. 
cumpliera lo convenido de otorgar el subsidio a la Universidad. Cuatro mil universitarios apoyaron y seis semanas después la SAG entregó becas, subsidio y posta zootécnica, y la huelga terminó. Después vino la huelga en la capital del país, a donde viajaron representantes de los estudiantes chihuahuenses. El 19 de septiembre, en Chihuahua, marcharon tres mil estudiantes de la Universidad, el Tecnológico, la Normal del Estado y la rural de Salaices para protestar la ocupación militar de la Universidad Nacional, en la Ciudad de México. Las sociedades de alumnos de Derecho y de Agronomía, y la Federación de Estudiantes de Chihuahua anunciaron que serían anfitriones del Segundo Encuentro Nacional Democrático Estudiantil y que esperaban a cerca de 300 dirigentes nacionales. El 2 de octubre, el Gobierno federal usó a cuerpos especiales de la policía y el ejército para atacar a los estudiantes reunidos en un mitin, en Tlatelolco, Ciudad de México. Tres días después de la masacre, varias escuelas de la Universidad de Chihuahua se declararon en huelga indefinida. La brutal represión menguó la fuerza de la huelga en la capital del país, que terminó en diciembre. Por el contrario, "en Chihuahua el movimiento no se debilitó... Nosotros salimos muy fuertes del movimiento del 68, porque teníamos la base esta de la Colonia Villa"27.

Probablemente el pilar más visible del Comité de Defensa Popular fue la organización de la Colonia Francisco Villa. La colonia fue fundada por familias que invadieron terrenos baldíos en la poco urbanizada zona norte de la ciudad de Chihuahua. El Frente Popular Inquilinario, bajo el liderazgo de Rodolfo Ramos Beltrán, organizó a más de mil jefes de familia para la ocupación de terrenos de propiedad privada. Este fue el segundo de dos intentos, y su éxito marcó el inicio de la Colonia Francisco Villa ${ }^{28}$.

Por supuesto la necesidad fue razón principal para llevar a cabo la ocupación. El núcleo urbano de Chihuahua era ya entonces incapaz de satisfacer la demanda de vivienda provocada por el aumento de

27 Entrevista a Orozco Orozco, Víctor, Ciudad Juárez, 6 de noviembre, 2016.

28 "Los invasores dicen que Giner los obligó a recurrir a medios extremos", El Heraldo, Chihuahua, 12 de junio, 1968, B1; “Desalojaron los terrenos del Seguro Social”, El Heraldo, Chihuahua, 14 de junio, 1968, B1; “Más de mil paracaidistas invaden” (fotografías), El Heraldo, Chihuahua, 28 de junio, 1968, B1; y "No se posesionaron de los terrenos del ejido", El Heraldo, Chihuahua, 29 de junio, 1968, B1. 
población. En el espacio de una generación, de 1930 a 1960, la ciudad había triplicado su población (de 61.526 a 186.089), y en los siguientes diez años creció $49 \%$, para sumar casi 280 mil $^{29}$. El rápido aumento fue debido a la inmigración, sobre todo proveniente de zonas rurales del mismo estado, con un número importante de inmigrantes de los estados de Durango, Coahuila y Zacatecas. Las vecindades en el centro de la ciudad estaban saturadas. En 1970, 277.099 residentes en la ciudad ocupaban 48.773 viviendas: $63 \%$ de esos residentes ocupaban viviendas de entre 1 y 3 cuartos, mientras que arriba de la mitad de las familias estaban compuestas por más de 5 miembros. En suma, la fuerte inmigración a la ciudad resultó en saturación y amontonamiento en las zonas residenciales.

Los inmigrantes constituían la mayoría entre quienes invadieron, especialmente aquellos cuya edad oscilaba alrededor de los 25 años. No obstante, más de una tercera parte eran nacidos en la ciudad ${ }^{30}$. Eran un conjunto variado y disímil, unidos por su condición de inmigrantes y de necesidad de vivienda y servicios. La invasión en sí parece haber tenido mucho de espontánea. Rubén Aguilar, que posteriormente se convertiría en líder de la colonia, recuerda que simplemente invitaron a la gente a posesionarse de los terrenos ${ }^{31}$. Pastor Rodríguez Sánchez y Manuel Sagarnaga Rodríguez declararon a la policía que, estando en la zona, advirtieron movimiento que les causó curiosidad, y cuando se acercaron a averiguar fueron invitados a unirse, porque "estaban repartiendo terrenos para la gente pobre", y les indicaron que tomaran "uno de los terrenos que previamente fueron medidos" 32 .

La necesidad de vivienda era razón importante, pero no suficiente para explicar por qué participar en la invasión. Quizás la acción estuvo

29 Censo General de Población, 1960: Estado de Chihuahua (Ciudad de México: Dirección General de Estadística, 1963); Censo General de Población, 1970: Estado de Chihuahua (Ciudad de México: Dirección General de Estadística, 1971); Víctor Orozco, "Las luchas populares en Chihuahua", Cuadernos Políticos No. 9 (1976): 53.

30 Ana Laura González Valdés, "Capital social y redes migratorias desde contextos urbanos. Colonia Villa Nueva, Chihuahua, Chihuahua" (tesis de maestría en Antropología Social, ENAH Chihuahua-CIESAS, 2009), 69-70.

31 Entrevista a Aguilar, Rubén, Chihuahua, 24 de octubre, 2019.

32 "Los chihuahuenses soportan un gobierno de puras promesas", El Heraldo, Chihuahua, 19 de julio, $1968,1$. 
también aconsejada por la idea de un derecho natural a la vivienda. Así lo expresó el líder Adán Sigala diez años después de la primera invasión. Respondiendo a las acusaciones de actuar fuera de la legalidad, él aseveró que junto a la necesidad operaba la determinación a "no renunciar al derecho natural de poseer un pedazo de tierra" 33 . La prontitud con que Pastor Rodríguez y Manuel Sagarnaga respondieron afirmativamente a la invitación a invadir terrenos, sugiere que compartían esta idea. Ellos eran inmigrantes, así como Sigala, quien emigró de Ignacio Zaragoza, una pequeña población agrícola en el noroeste del estado ${ }^{34}$. Otro de los líderes, Jesús Güereca, provenía de una pequeña localidad rural en Durango, y llegó a la ciudad junto con sus hermanos ${ }^{35}$. En otras palabras, estos líderes compartían el origen rural y la condición de inmigrante con muchos de los invasores; compartían con ellos la idea de que la tierra y la vivienda no eran una mercancía, sino un derecho natural.

Pero por supuesto hubo organización. La invasión fue planificada por el Frente Inquilinario. El dirigente Rodolfo Ramos Beltrán lo encontramos, en 1964, en el comité de huelga de la Normal estatal. En 1966, acorde a la memoria de Jaime García Chávez, pertenecía a la célula Turcio Lima del Partido Comunista ${ }^{36}$. Sigala ingresó al club Carlos Marx de la Juventud Comunista cuando estudiaba en la Preparatoria, y en 1967 participó en la fundación del Frente Revolucionario Estudiantil Preparatoriano ${ }^{37}$. Víctor Orozco recuerda que él, Jaime García Chávez, Rubén Aguilar y varios otros Nachos, como eran conocidos los miembros de la Sociedad Ignacio Ramírez de la Facultad de Derecho, estaban involucrados con los problemas de vivienda en la ciudad y participaban, a la par del Partido Comunista, en el Frente Inquilinario ${ }^{38}$. El propósito

33 "Del 'paracaidismo' al derecho a la tierra", Proceso, Ciudad de México, 29 de diciembre, 1979, 48.

34 "Doña Francisca Juárez Miramontes", El Heraldo de Chihuahua, Chihuahua, 25 de enero, 2018 https://www.pressreader.com/mexico/el-heraldo-de-chihuahua/20180225/283137134279514, (consultado 19/11/2019).

35 "Tres hermanos, tres vidas", El Heraldo de Chihuahua, Chihuahua, 15 de abril, 2018 https:// www.pressreader.com/mexico/el-heraldo-de-chihuahua/20180415/282870846405657 (consultado 19/11/2019).

36 Jaime García Chávez, "Arnoldo Martínez Verdugo", Oseri, cultura y derechos humanos, Chihuahua, 12 de enero, 2013, http://uri.oseri.net/index.php?option=com_content\&task=view\&id=2086\&Itemid $=$ (consultado 20/12/2019). 
deliberado tradujo la necesidad y la idea de derecho natural en la acción de expropiar los terrenos.

Los estudiantes participaron en la invasión de terrenos y, en reciprocidad, los colonos de la Villa salieron con ellos a protestar por los asesinatos del 15 de enero. José Manuel recuerda que "la interrelación y la solidaridad ya existía" y por eso los colonos estuvieron dispuestos "para protestar por los asesinatos extrajudiciales de muchachos acelerados que se habían montado a la ola de respuesta a la represión del 68"39. Ese apoyo fue importante, porque la colonia era conocida en la ciudad por su combatividad.

El tercer pilar del CDP fueron los sindicatos. La ciudad era sede de las secciones de ferrocarrileros, electricistas y maestros, sindicatos nacionales en ese momento envueltos en broncas internas, además de sus enfrentamientos con las instituciones gubernamentales que empleaban a sus miembros. En algunos casos, la perspectiva de los sindicalistas disidentes rebasaba el ámbito laboral, porque pertenecían a organizaciones que planteaban un programa de transformación para la sociedad mexicana. Junto a ellos, se sumó un sindicato local, de la empresa Aceros de Chihuahua, que en esos días luchaba por asegurar su independencia y lograr efectividad frente a la empresa. El Frente Auténtico del Trabajo, también incorporado al CDP, provenía de la democracia cristiana y perseguía la creación de una central sindical que fuera democrática, independiente y combativa. Las organizaciones sindicales componían un variado mosaico, pero coincidían en reconocer la necesidad de unidad.

Más de diez años antes, los trabajadores del ferrocarril protagonizaron importantes huelgas en 1958 y 1959, antecedidas por un fuerte movimiento de base para expulsar a líderes espurios. El triunfo inicial de entonces pronto se convirtió en represión, persecución y cárcel ${ }^{40}$. Dos de los líderes encarcelados, Valentín Campa y Demetrio Vallejo, salieron en 1971, y regresaron al activismo sindical: Campa con el Partido

40 Mario Gill, Los ferrocarrileros (Ciudad de México: Extemporáneos, 1971), 162-204; Antonio Alonso, El movimiento ferrocarrilero en México, 1958-1959 (Ciudad de México: Era, 1972). 
Comunista, mientras que Vallejo inició el Movimiento Sindical Ferrocarrilero. El programa del MSF era sencillo: botar a líderes corruptos, democratizar el sindicato, y colaborar en la construcción de solidaridad necesaria entre sindicatos para emprender la insurgencia sindical. El MSF también se opuso al plan de reajuste que amenazaba con despidos y recorte de prestaciones para así reducir los costos de operación, requisito para obtener un préstamo y modernizar a Ferrocarriles Nacionales. Los disidentes propusieron, en cambio, eliminar la corrupción de la administración y la alta burocracia sindical, causa del elevado costo de operación, y aumentar las tarifas de flete a las empresas, que estaban muy por debajo del costo real de transporte. El aumento en los ingresos por transporte de carga podría, inclusive, financiar aumentos en salarios, jubilaciones y otras prestaciones. El MSF proponía no solo cambios en la dirección sindical, sino también en la administración patronal ${ }^{41}$.

El primer paso consistía en oponerse al nuevo comité ejecutivo nacional, debido al desaseo en la elección que le dio el triunfo. La táctica central consistió en ocupar los locales sindicales, para forzar nuevas elecciones. Por ello, en 1971, la sección de Chihuahua del MSF estaba a la cabeza del activismo sindical en la ciudad. Los ferrocarrileros disidentes ganaron fuerza desde mayo y en octubre lograron apoderarse del edificio y destituir a los charros. La burocracia sindical, desde las oficinas nacionales en la Ciudad de México, envió golpeadores rumbo a distintas ciudades del país, para encarar la disidencia. El MSF en Chihuahua optó por desocupar el edificio sin violencia ${ }^{42}$.

Los maestros atravesaban por su propia lucha intestina. La sección 8, de Chihuahua, ganó una huelga en 1956 y mejoró la condición de sus miembros ${ }^{43}$. En los siguientes dos años, los maestros en el Distrito Federal llevaron a cabo una serie de acciones y luchas para mejorar sus salarios y en oposición a la dirección nacional del sindicato, bajo la

41 "Entrevista con Demetrio Vallejo", Punto Crítico, Ciudad de México, abril, 1972, 36-41; "Reajuste en ferrocarriles", y "Demandas económicas del M.S.F.", El Martillo, Chihuahua, 1 y 15 julio, 1972, 3.

42 “Insurgencia sindical, 1971", Punto Crítico, Ciudad de México, enero, 1972, 26-27; "El Movimiento Sindical Ferrocarrilero hace un balance de su actuación”, Punto Crítico, Ciudad de México, noviembre, 1972, 13.

43 Aurora Loyo Brambila, El movimiento magisterial de 1958 en México (Ciudad de México: Era, 1979), 35. 
bandera del Movimiento Revolucionario del Magisterio; el movimiento decayó después de la derrota de los ferrocarrileros y los líderes espurios se impusieron ${ }^{44}$. El MRM se expandió a algunas otras secciones del sindicato, y a fines de la siguiente década, los maestros nuevamente emprendieron la lucha, encabezados por el Movimiento Revolucionario del Magisterio. El MRM en Chihuahua era dirigido por Antonio Becerra Gaytán, quien desde 1964 era secretario general del Partido Comunista en el estado ${ }^{45}$.

Los trabajadores electricistas enfrentaban una situación diferente. La electricidad fue nacionalizada en 1960, y los tres sindicatos que entonces tenían contratos colectivos en la industria firmaron convenios para asegurar el reconocimiento y respeto mutuo. Sin embargo, en 1970, el secretario general Pérez Ríos, del Sindicato Nacional de Electricistas, Similares y Conexos de la República Mexicana (SNESCRM), perteneciente a la Confederación de Trabajadores de México (CTM), desconoció dichos convenios y entró en disputa con el Sindicato de Trabajadores Electricistas de la República Mexicana (STERM), con el objetivo de ser titular único del contrato con la Comisión Federal de Electricidad, la agencia federal encargada de administrar la generación de energía eléctrica. El Sindicato Mexicano de Electricistas se mantuvo distante del conflicto intergremial, porque representaba solo a los trabajadores de Luz y Fuerza del Centro, empresa también pública pero aparte de la Comisión. En octubre de 1971, la Junta Federal de Conciliación y Arbitraje concedió al SNESC la titularidad del contrato de la Comisión. El STERM, dirigido por Rafael Galván, pidió a la Corte Suprema un amparo contra la decisión, al mismo tiempo que lanzó un llamado a la democratización del movimiento obrero. Galván, quien pertenecía al ala izquierda del nacionalismo revolucionario dentro del Partido Revolucionario Institucional, consideró que había un choque entre la tendencia democrática, a la que decía representar, y la tendencia charra encabezada por Fidel Velázquez, máximo dirigente de la CTM;

44 Aurora Loyo Brambila, Movimiento magisterial.

45 Olga Aragón, "Antonio Becerra, seis décadas de congruencia... desde la izquierda", (Chihuahua: 4Vientos TV entrevistas, 2019), http://www.4vientos.net/2019/01/15/4v-tv-entrevistas-antonio-becerra-seis-decadas-de-congruencia-desde-la-izquierda/ (consultado: 20/12/2019); Grupo de Trabajo, "Chihuahua 1972", 7-8. 
calificó a Pérez Ríos de charro subordinado a la CTM ${ }^{46}$. Los electricistas en Chihuahua, la sección 25 del STERM, llevaron a cabo acciones de apoyo a la dirección nacional y contra el fallo de las autoridades laborales respecto de la titularidad del contrato colectivo ${ }^{47}$.

Los trabajadores del riel actuaron como vanguardia y cohesionaron los distintos conflictos y organizaciones obreras. Su lucha por destituir a la dirección fraudulenta, en 1971, obtuvo el apoyo de electricistas, acereros, maestros y colonos de la Pancho Villa. Por eso decidieron no enfrentar la embestida de la dirigencia nacional y, en cambio, laborar a favor de crear una alianza de los obreros sindicalizados en la ciudad. Iniciaron conversaciones para formar "una organización más amplia, principalmente con los compañeros que nos habían dado todo su apoyo, para formar una alianza obrero-campesino-estudiantil, donde quedaran clarificadas algunas cuestiones que la experiencia de luchas pasadas nos había enseñado" ". Compartían, como afirmó el dirigente local del MSF, Manuel Valles Muela, el objetivo de derrocar al charrismo, que era la "base de sustentación del gobierno represivo que padecemos". El profesor Becerra Gaytán también comentó sobre la convergencia de las luchas previo al triple asalto y la formación del CDP: los electricistas, los acereros y los estudiantes de la universidad sentían "la necesidad de la creación de un organismo que pueda brindar solidaridad a los distintos destacamentos", y se juntaron entre ellos y con colonos y ferrocarrileros "a deliberar sobre el problema de la organización para dar la lucha contra el charrismo, contra la represión”. Los sindicalistas y sus aliados tenían programada una reunión para concretar un programa de acción, que debía realizarse a fines de enero de 1972; no se llevó a cabo porque la alianza ocurrió de hecho en las movilizaciones y la creación del $\mathrm{CDP}^{49}$.

46 "Insurgencia sindical", 25-26; para un examen contemporáneo del conflicto, véase Silvia Gómez Tagle y Marcelo Miquet, "Integración o democracia sindical: el caso de los electricistas", en Tres estudios sobre el movimiento obrero en México, eds. José Luis Reyna et al. (Ciudad de México: El Colegio de México, 1976), 151-202.

47 "Panorama general de la situación política del país reportada a la Dirección Federal de Seguridad (D.F.S.)" (13 de diciembre, 1971), AR, DFS informes diarios, https://biblioteca.archivosdelarepresion.org $/ \mathrm{s} / \mathrm{comverdad} / \mathrm{item} / 44857 \#$ ? $\mathrm{c}=\& \mathrm{~m}=\& \mathrm{~s}=\& \mathrm{cv}=67 \& \mathrm{xywh}=1070 \% 2 \mathrm{C}-74 \% 2 \mathrm{C} 5362 \%$ 2C3364\&r (consultado: 17/12/2019).

48 Grupo de Trabajo, “Chihuahua 1972”, pp.7-8; Víctor Orozco, "Luchas,” 59-60.

49 Grupo de Trabajo, "Chihuahua 1972", 7-8. 
La convergencia de estas luchas fue en parte resultado de su coincidencia en tiempo y lugar. La otra parte fue el importante impulso provisto por las redes de relación de un pequeño grupo de militantes. Las instituciones de enseñanza media y superior y el Partido Comunista o alguna otra organización de izquierda dispusieron el escenario que alentó coincidencias de ese tipo. Diego Lucero Martínez, estudiante universitario de ingeniería, y Víctor Orozco, estudiante universitario de derecho, formaron parte del grupo de apoyo del GPG en 1965; de la misma manera, Jaime García Chávez y Rubén Aguilar Jiménez fueron compañeros de Óscar González Eguiarte en la Facultad de Derecho, y los primeros dos fueron parte del GPGAG de 1968, comandado por González Eguiarte. En 1966, Jaime García Chávez, Rogelio Luna y Rodolfo Ramos Beltrán pertenecían a la célula Turcio Lima, en el Partido Comunista local, cuyo secretario general era Antonio Becerra Gaytán. En 1964, Rodolfo Ramos Beltrán estuvo en el comité de huelga con Emma Becerra Gaytán, hermana de Antonio, y en 1968 lo encontramos dirigiendo el Frente Inquilinario. Los huelguistas en 1964 recibían asesoría de varias organizaciones, entre ellas, el Movimiento de Liberación Nacional, y Víctor Orozco recuerda encontrar por primera vez a Rubén Aguilar en un mitin para protestar la invasión a Playa Girón, en 1961, organizada por el MLN, del que Rubén ya era miembro.

Lucero Martínez, cuando secretamente regresó a Chihuahua, invitó a su prima Avelina Gallegos a participar en la expropiación de sucursales bancarias del Grupo Chihuahua, propiedad de la familia Vallina, que también poseía terrenos forestales demandados por integrantes del GPG en 1965. Avelina pertenecía al grupo Las Rosas, un colectivo de mujeres estudiantes de leyes que coincidían en edad con Lucero, Orozco, García Chávez y Aguilar. ${ }^{50}$ Lucero Martínez reclutó a otros dos participantes, Francisco Javier Pizarro Chávez y Marco Rascón Córdova. José Luis Pallares fue el enlace con la generación más joven de Pizarro y Rascón; él perteneció al Club Carlos Marx, de la Juventud Comunista, que agrupaba a estudiantes de la preparatoria de la UACH, entre ellos, Adán Sigala y Carlos David Armendáriz Ponce. Estos jóvenes comunistas a

$50 \quad$ Nithia Castorena Sáenz, Estaban ahí. Las mujeres en los grupos armados de Chihuahua (1965-1972) (Ciudad Juárez: Universidad Autónoma de Ciudad Juárez, 2019), 174-182. 
su vez iniciaron el Frente Revolucionario Estudiantil Preparatoriano, en el que también militaron Cecilia Rascón, Marco Rascón, el Búho, y Froilán Rascón. En 1968, los llamados Frepos imprimían sus volantes en el mimeógrafo de Los Nachos, en Derecho ${ }^{51}$.

La colonia y el trabajo juntaron a otros en redes que aún no podemos señalar con nombre y apellido. Sabemos, por ejemplo, que muchos residentes de la Colonia Villa trabajaban en Aceros de Chihuahua, porque la empresa era vecina de la colonia. También vivían ahí trabajadores ferrocarrileros ${ }^{52}$. Probablemente, muchos egresados de la Normal estatal encontraron trabajo en las escuelas de la zona, que empezó a crecer en población desde fines de los años cincuenta. Así lo hizo Alma Gómez, a mediados de los setenta; ella era hija de Pablo Gómez, uno de los dirigentes del GPG muerto en Madera ${ }^{53}$. En fin, encontramos en la constitución del Comité y de los movimientos individuales que lo antecedieron, las redes de relaciones y los sistemas de acción que Melucci señala como característica importante de la acción colectiva concertada. ${ }^{54}$ Esas redes constituyeron un núcleo no necesariamente homogéneo de militantes, pero sí de activistas fogueados en variedad de conflictos y dispuestos a organizar para transformar la sociedad.

\section{EL CDP: 1972-1973}

El CDP era un frente político, y a la vez, una coordinación en la práctica para las diferentes luchas sociales en curso. La aspiración era convertir todas estas luchas, sin subordinarlas, en un solo empuje. Un viejo ferrocarrilero, recurriendo a las enseñanzas del pasado, consideraba que en 1958 los ferrocarrileros habían sufrido por su aislamiento, y por eso ahora el camino era "no solamente luchar por una causa, sino por todas las causas que atañen no solo al ferrocarrilero, sino al electricista, al estudiante, al maestro y al pueblo en general" 55 .

\footnotetext{
51 Juan Chávez de la Rocha, "A 50 años".

52 Ana González Valdés, "Capital social", 69-70.

53 Entrevista a Gómez, Alma, Chihuahua, Chih., 22 octubre, 2019.

54 Alberto Melucci, Acción colectiva, vida cotidiana y democracia (Ciudad de México: El Colegio de México, 1999), 11-12.

55 “Chihuahua 1972", 11.
} 
La primera prueba de unidad ocurrió casi simultánea a la organización del Comité. En 1972 estallaron huelgas estudiantiles escalonadas, en la estela de las movilizaciones contra la represión. La primera huelga inició en la Universidad Autónoma de Chihuahua el 14 de febrero, siguió el Instituto Tecnológico Regional el 28, y finalmente fueron a paro los estudiantes de la Normal, el 6 de marzo ${ }^{56}$. La huelga universitaria logró la paridad de representación en el Consejo Universitario, la abolición de la Junta de Gobierno, y la instalación de comisiones negociadoras, de manera que los estudiantes regresaron a clases el 7 de marzo ${ }^{57}$. Los estudiantes normalistas regresaron el 23 , después de ganar varias de sus demandas, aunque algunas en versión diluida ${ }^{58}$. La huelga en el Tecnológico se prolongó hasta mediados de mayo. La Normal y el Tecnológico dependían de la Secretaría de Educación Pública, es decir, del Gobierno federal, que se oponía a conceder paridad. En el caso de la Normal, la intervención del gobernador logró instalar un consejo técnico regido por las normas de la SEP y restringir el derecho a veto del director, que los estudiantes exigían se eliminara. En el caso del Tecnológico, el CDP hizo suya la demanda de convertir los consejos consultivos en resolutivos y con representación paritaria, razón por la que el 8 de mayo CDP y estudiantes tomaron el Palacio de Gobierno por varias horas, y para el 10 de mayo habían obtenido el consejo paritario $^{59}$.

La ciudad experimentaba una actividad política sin precedente. El 9 de marzo, con el Tecnológico y la Normal en huelga, se celebró un mitin de la Asamblea Popular, en la plaza central, que aprobó constituir el Tribunal Popular para juzgar a las autoridades involucradas en la muerte de los jóvenes insurgentes. El orador principal fue el líder ferro-

56 “Tras prolongada asamblea la huelga se inició ayer desde las 10:30 HS.", Norte, Chihuahua, 15 de febrero, 1972, 1; "Perspectivas de solución al problema estudiantil del Tecnológico Regional", Norte, Chihuahua, 29 de febrero, 1972, 1; "Huelga estudiantil en la Escuela Normal del Estado", Norte, Chihuahua, 7 de marzo, 1972, 1.

57 "Quedará abolida la Junta de Gobierno de la Universidad", Norte, Chihuahua, 2 de marzo, 1972, 1; "Retornan a las aulas desde hoy los estudiantes universitarios", Norte, Chihuahua, 7 de marzo, 1972, 1.

58 "Se reanudaron las labores en la Escuela Normal del Estado, ayer", Norte, Chihuahua, 23 de marzo, $1972,1$.

59 "Inminente solución de la huelga en el Tecnológico", Norte, Chihuahua, 9 de mayo, 1972, 1; "Los estudiantes entregan mañana las instalaciones", Norte, Chihuahua, 10 de mayo, 1972, 1; "En Chihuahua: otra victoria popular", Punto Crítico, Ciudad de México, mayo, 1972, 31. 
carrilero Demetrio Vallejo y posteriormente intervinieron estudiantes del Tecnológico, la Normal, la UACH, el STERM y un representante de la Escuela Nacional de Antropología e Historia ${ }^{60}$.

La idea del tribunal popular fue un golpe de genialidad y astucia política. Hasta ese momento, eran los políticos y la élite empresarial quienes lanzaban acusaciones de violencia a sus opositores. La creación del tribunal popular revertía los cargos. Más adelante, en julio, el CDP invitó a todas las organizaciones que quisieran participar, y llevó la jurisdicción del tribunal más allá de los sucesos locales: el Gobierno mexicano sería juzgado "por la utilización de la represión como método o sistema de gobernar" ${ }^{61}$. El CDP respondía a la violencia del Estado con el derecho popular a enjuiciar a los gobernantes, muy distinta respuesta a la represiva acostumbrada por el Estado.

El Tribunal Popular fue instalado el 26 de julio en la Plaza de Armas. Participaron como oradores por el CDP Antonio Becerra Gaytán y Rubén Aguilar, y después varios oradores invitados, entre ellos, Valentín Campa, Danzos Palomino y Othón Salazar, reconocidos miembros del Partido Comunista. Pasadas varias reuniones, el tribunal emitió su fallo el 2 de octubre de 1972: encontró culpables al presidente Luis Echeverría, al gobernador de Chihuahua, Oscar Flores, y al conjunto del "gobierno de la burguesía mexicana" de cometer "múltiples crímenes, asesinatos y demás actos represivos en contra del pueblo trabajador". Por esa razón, condenó al Gobierno a "ser liquidado total y definitivamente" y a la burguesía a "ser destruida como clase, para eliminar el sistema capitalista". La declaración terminaba llamando al pueblo a "ejecutar esta sentencia, acabando con el gobierno de la burguesía e implantando un gobierno de los trabajadores" y a utilizar todos los medios revolucionarios "necesarios para su ejecución"

El CDP reivindicaba una legalidad distinta a la existente, y en tanto el movimiento social, respaldaba sus manifestaciones públicas con la fuerza

60 "Exigen la consignación del Inspector General de Policía y del Procurador", Norte, Chihuahua, 10 de marzo, 1972, 1.

61 "Tribunal Popular", El Martillo, Chihuahua, 1 de julio, 1972, 4.

62 "La sentencia", El Martillo, Chihuahua, 2 de octubre, 1972, 2. 
de la movilización masiva. No obstante, no reculó de usar la violencia política cuando era necesaria. En enero de 1972, el MSF decidió reanudar la toma de los edificios sindicales, porque representaban "el corazón de la organización" y tenían materiales y espacio necesarios para la organización. La toma en Chihuahua ocurrió el 4 de octubre de 1972. Manuel Valles Muela había sido electo secretario de la sección un año antes; ahora, nuevamente reunidos en asamblea, la base ferrocarrilera ratificó su elección y la expulsión de los charros. Estos últimos, reforzados por una organización paramilitar, los Halcones, atacaron a los ocupantes del edifico al amanecer del día 6. Los atacantes, a palos y balazos, fueron exitosos al principio, logrando ingresar y quemar el archivo. Los del MSF organizaron el contraataque. La batalla callejera duraba ya casi dos horas cuando los trabajadores del taller de ferrocarriles, que salieron de su turno a las siete de la mañana, se unieron a la defensa del edificio. A las 9 de la mañana llegaron refuerzos del Comité de Defensa Popular, sobre todo residentes de la Colonia Villa y estudiantes. Mientras tanto, la policía y el ejército que se habían mantenido como observadores de la gresca, entraron a reforzar el lado de los atacantes. Aun así, el ataque fue repelido y el edificio permaneció en manos del MSF. Por la tarde, una gran manifestación frente a las oficinas del gobernador exigió la liberación de los detenidos por parte del MSF y castigo a los agresores. Para entonces, ya los charros y Halcones se habían escabullido sin dejar rastro ${ }^{63}$.

La lucha del MSF fue con frecuencia violenta. En Matías Romero, Oaxaca, los charros atacaron el edificio sindical a balazos, en los últimos días de 1972. Los ferrocarrileros democráticos respondieron al fuego, para defenderse, y mataron a los dos atacantes. En consecuencia, quienes procedieron en defensa propia fueron arrestados bajo el cargo de homicidio. La dirección nacional del MSF acordó movilizaciones en enero y en febrero de 1973 para exigir la libertad de los detenidos. El 14 de enero hubo manifestaciones masivas en Guadalajara, Monterrey, Ciudad Frontera, Tampico, Irapuato, Oaxaca y varias otras ciudades. En Chihuahua marcharon alrededor de 700 personas entre ferrocarrileros

63 "Victoria popular", "El M.S.F., los charros y el Estado", El Martillo, Chihuahua, 7 de octubre, 1972, 1, y 10 de octubre, 1972, 4. 
y otros sindicalistas, y 2.500 se congregaron en el mitin en la plaza de armas. Los miembros del MSF en el país nuevamente salieron a la calle el primero de febrero. En Chihuahua, al igual que en la marcha anterior, los ferrocarrileros marcharon acompañados por el CDP, y culminaron su protesta con un mitin en la plaza de $\operatorname{armas}^{64}$.

Los primeros años del CDP siguieron en este tenor. Hacia el final de la década de 1970 declinaron las movilizaciones, al mismo tiempo que las divisiones internas arreciaron. En consecuencia, el CDP dejó de ser un vehículo efectivo para expresar el descontento común. El CDP identificado con la colonia Villa y otras colonias populares, se convirtió en una organización de presión política y, años más tarde, devino partido político (primero conservando su nombre y después integrándose al Partido del Trabajo ${ }^{65}$. Habrá que estudiar la trayectoria completa, y muy en particular los primeros años, en los que experiencia y expectativa de una transformación social radical parecían fusionarse.

\section{ConClusión}

Desde fines de los años cincuenta ocurrieron, en todo México, luchas sociales que exigían mejoras en la vida material, democracia y respeto a los derechos civiles. El Gobierno respondió en todos los casos con extrema represión. La experiencia acumulada y, combinada con el impacto que tuvieron la Revolución Cubana y las guerras anticoloniales y antiimperialistas en Vietnam y países de África, propició la radicalización hacia la izquierda de estas luchas, e incluso tornó atractiva la oposición armada socialista. En Chihuahua hubo continuidad entre los grupos armados desde 1965 hasta 1972, cuando ocurrió el fallido triple asalto bancario comandado por Diego Lucero. A consecuencia de las ejecuciones extralegales llevadas a cabo por la policía, la población de la ciudad se volcó a las calles. En semanas de intensa movilización para demandar castigo al Procurador de justicia en el Estado y al jefe de la

64 “MSF ante la represión: ¡Movilización!”, Punto Crítico, Ciudad de México, febrero, 1973, 15; “En los frentes de lucha. Manifestación del MSF", El Martillo, Chihuahua, 3 de febrero, 1973, 4.

65 Rubén Lau, "Historia política del CDP", en Movimientos populares en Chihuahua, eds. Rubén Lau y Víctor Quintana Silveyra (Ciudad Juárez: Universidad Autónoma de Ciudad Juárez, 1991), 12-68. 
policía de la ciudad, surgió el Comité de Defensa Popular, una alianza entre colonos populares, trabajadores sindicalizados y estudiantes.

Esta secuencia de sucesos explica en parte el surgimiento del CDP, pero no explica las características que adquirió la organización. El Comité era una gran alianza popular, cuya unión, acorde a Rubén Aguilar, había nacido en la base y no en la cúpula. Entendido como un movimiento social, la aparición del CDP no fue el inicio, sino el punto de llegada de un proceso que puede trazarse varios años hacia atrás. Por eso sería más apto decir que la alianza nació de una red de relaciones forjada a través de experiencias de conflicto y solidaridad.

No es el propósito de este estudio ir más allá de la fundación del Comité. Por supuesto, habrá que estudiar los años posteriores. Durante los primeros años de la organización, algunos dirigentes intentaron crear un parlamento popular que fungiera como coordinación general de luchas locales, tratando de expandir su influencia a otras ciudades del estado. Después vinieron rupturas y cambios de dirección y todavía resta comprender sus causas y consecuencias. Hay que considerar, además, que el optimismo y las posibilidades que para unos significó el CDP, para otros significó amenaza. El giro cualitativo de la lucha social convenció a los gobiernos local y federal y a empresarios regionales de emprender una acción represiva generalizada, pero en particular dirigida a exterminar los grupos armados e inhibir el desborde de la protesta social hacia la insurgencia. Los procedimientos y las consecuencias de esta represión también habrá que estudiarlos, desarrollándose a la par que avanzaba el movimiento social.

Finalmente, hay que estudiar los procesos que enmarcan la manifestación abierta del movimiento para entender sus causas. Para citar nuevamente a Melucci, son esos aspectos de la lógica sistémica, que no aparecen a simple vista, los que revelan causas estructurales y subjetivas que explican los sucesos ${ }^{66}$. Esta última esfera de estudio tampoco la hemos tocado aquí, porque la intención de este análisis es otra. No obstante, vale la pena esbozar brevemente ese universo de cambios

66 Alberto Melucci, Acción colectiva, 53-54. 
estructurales que afectó a la sociedad de Chihuahua en la segunda mitad del siglo XX, al igual que al resto del país ${ }^{67}$.

Los estudiosos coinciden en señalar que la decisión de industrializar el país, en los años posteriores a la Segunda Guerra Mundial, afectó adversamente al campo ya que derivó la ganancia obtenida en la agricultura hacia la inversión urbana e industrial. Al mismo tiempo, el contragolpe de los grandes propietarios agrarios, que lograron anular las leyes de reforma agraria, socavaron la esperanza campesina de acceder a la propiedad por la vía de la dotación de tierras. La agudización de la lucha por la tierra fue uno de los resultados de esta situación; el otro fue la emigración masiva de la población rural hacia los centros urbanos. Ahí, la expectativa de lograr una buena vida renació debido al crecimiento industrial y el aumento sostenido de los salarios después de 1955 y hasta mediados de los setenta. Por contraste, los migrantes rurales encontraron condiciones urbanas adversas y en los lugares de trabajo toparon con modos de trabajar que chocaban con sus costumbres, causa de tensión cotidiana con la disciplina industrial. Además, convivían con obreros de segunda y tercera generación, experimentados en luchas laborales, que chocaban con las políticas de industrialización que requerían sindicatos bajo control gubernamental y trabajadores quietos y contentos. Por último, el sistema político mexicano viró hacia un mayor conservadurismo y autoritarismo, el momento contrarrevolucionario posterior al periodo presidencial de Cárdenas, de manera que la Guerra Fría en México fue dirigida no solo contra los comunistas, sino sobre todo contra la fuerza que conservaba el cardenismo ${ }^{68}$. Las aspiraciones liberales y democráticas de la clase media urbana y de los jóvenes hijos de campesinos y obreros que aspiraban a obtener el progreso que el discurso político prometía, toparon con este embate conservador y optaron por derribarlo.

67 Las siguientes líneas están basadas en Juan Carlos Moreno-Brid y Jaime Ros Bosch, Desarrollo y crecimiento en la economía mexicana: una perspectiva histórica (Ciudad de México: Fondo de Cultura Económica, 2010); Luis Medina Peña, Hacia el nuevo estado: México, 1920-1993 (Ciudad de México: Fondo de Cultura Económica, 1994); Lorenzo Meyer, La segunda muerte de la Revolución Mexicana (Ciudad de México: Cal y Arena, 1992).

68 Lorenzo Meyer, "La guerra fría en el mundo periférico: el caso del régimen autoritario mexicano. La utilidad del anticomunismo discreto", en Espejos de la guerra fría, coord. Daniela Spenser (Ciudad de México: Ciesas, Porrúa, 2004), 95-117. 
Es en este amplio contexto que encontramos las oposiciones estructurales que propiciaron los procesos que animaron el surgimiento de movimientos sociales. Estos movimientos sociales perseguían mejoras en las parcelas de vida que les tocó vivir a sus protagonistas. La inusual convergencia de estas oleadas de lucha social, en Chihuahua en los primeros años setenta, acercó el horizonte del futuro utópico vislumbrado por quienes luchaban por una sociedad socialista.

\section{Bibliografía}

\section{FUENTES PRIMARIAS}

\section{Archivos}

Archivos de la Represión (AR), Artículo 19, Colegio de México, Ciudad de México, México. https://archivosdelarepresion.org/ Recurso en línea que contiene copias de expedientes de la Dirección Federal de Seguridad, Dirección General de Investigaciones Políticas y Sociales, Secretaría de la Defensa Nacional y otras organizaciones policiales producidos entre 1950 y 1980, y cuyos originales están resguardados en el Archivo General de la Nación.

Colección MIDAS 3.

Colección MIDAS 6.

\section{Publicaciones periódicas}

El Fronterizo, Ciudad Juárez (diario, 1967-1968) .

El Heraldo, Chihuahua (diario1965, 1968, 1972, 2018).

El Martillo, Chihuahua (quincenal, 1972-1973).

Norte, Chihuahua (diario, 1972).

Proceso, Ciudad de México (semanal, 1979).

Punto Crítico, Ciudad de México (mensual, 1972-1973).

\section{ENTREVISTAS DE HISTORIA ORAL}

Entrevista a Aguirre Jiménez, Rubén, Chihuahua, 24 de octubre de 2019.

Entrevista a García Chávez, Jaime, Chihuahua, 21 de agosto de 2013. Entrevista a Gómez, Alma, Chihuahua, 22 de octubre de 2019. 
Entrevista a Muñoz, José Manuel, Ciudad de México, 14 de diciembre de 2016.

Entrevista a Orozco, Víctor, Cd. Juárez, 6 de noviembre de 2016.

\section{Fuentes Secundarias}

Aragón, Olga. "Antonio Becerra, seis décadas de congruencia... desde la izquierda”. Chihuahua: 4Vientos TV Entrevistas, 2019. http:// www.4vientos.net

Bartra, Armando. Guerrero Bronco, campesinos, ciudadanos y guerrilleros en la Costa Grande. Ciudad de México: Era, 2000.

Castellanos, Laura. México armado, 1943-1981. Ciudad de México: Era, 2007.

Castorena Sáenz, Nithia. Estaban ahí. Las mujeres en los grupos armados de Chihuahua (1965-1972). Ciudad Juárez: Universidad Autónoma de Ciudad Juárez, 2019.

Cedillo, Adela y Fernando Herrera Calderón. "Análisis de la producción historiográfica en torno a la llamada guerra sucia mexicana". En El Estudio de las Luchas Revolucionarias en América Latina (1959-1996): Estado de la Cuestión, editado por Martín López Ávalos, Verónica Oikión, y Eduardo Rey Tristán. Zamora: El Colegio de Michoacán \& Universidad de Santiago de Compostela, 2014, 263-288.

Censo General de Población, 1960: Estado de Chihuahua. Ciudad de México: Dirección General de Estadística, 1963.

Censo General de Población, 1970: Estado de Chihuahua. Ciudad de México: Dirección General de Estadística, 1971.

Chávez de la Rocha, Juan. "A 50 años, mis recuerdos...”. La Parada Digital, Ciudad Juárez, 4 de octubre, 2018, https: / laparadadigital. com/mis-recuerdos/ (consultado 19/11/2019).

De los Ríos Merino, Alicia. "La huelga de 1967 en la ESAHE”. Chihuahua Hoy Vol. 14 (2016): 113-147.

García Aguirre, Aleida. La revolución que llegaría. Ciudad de México: Edición de autora, 2015.

García Chávez, Jaime. “Arnoldo Martínez Verdugo”. Oseri, cultura y derechos humanos, Chihuahua, 12 de enero, 2013, http://uri.oseri. net $/$ index.php?option $=$ com_content\&task $=$ view $\&$ id $=2086 \&$ Ite$\operatorname{mid}=($ consultado 20/12/2019). 
Gill, Mario. Los ferrocarrileros. Ciudad de México: Editorial Extemporáneos, 1971.

Glockner, Fritz. Los años heridos. La historia de la guerrilla en México 1968-1985. Ciudad de México: Planeta, 2019.

Gómez Tagle, Silvia y Marcelo Miquet. "Integración o democracia sindical: el caso de los electricistas". En Tres estudios sobre el movimiento obrero en México, editado por José Luis Reyna et al. Ciudad de México: El Colegio de México, 1976, 151-202.

González Valdés, Ana Laura. "Capital social y redes migratorias desde contextos urbanos. Colonia Villa Nueva, Chihuahua, Chihuahua". (Tesis de maestría en Antropología Social, ENAH Chihuahua-CIESAS, 2009).

Henson, Beth. Agrarian Revolt the Sierra of Chihuahua 1959-1965. Tucson: Arizona State University, 2019.

Huacuja, Mario y José Woldenberg. Estado y lucha política en el México actual. Ciudad de México: Ed. El Caballito, 1976.

Jiménez Guzmán, Héctor. El 68 y sus rutas de interpretación. Ciudad de México: Fondo de Cultura Económica, 2018.

Lau, Rubén. "Historia política del CDP”. En Movimientos populares en Chihuahua, editado por Rubén Lau y Víctor Quintana Silveyra. Ciudad Juárez: Universidad Autónoma de Ciudad Juárez, 1991, 12-68.

Loyo Brambila, Aurora. El movimiento magisterial de 1958 en México. Ciudad de México: Era, 1979.

Lucero Estrada, Diego. Sueños Guajiros. Diego Lucero y la guerrilla mexicana de los años 60 y 70. Ciudad de México: Casa de las palabras, 2012.

Medina Peña, Luis. Hacia el nuevo estado: México, 1920-1993. Ciudad de México: Fondo de Cultura Económica, 1994.

Melucci, Alberto. Acción colectiva, vida cotidiana y democracia. Ciudad de México: El Colegio de México, 1999.

Meyer, Lorenzo. "La guerra fría en el mundo periférico: el caso del régimen autoritario mexicano. La utilidad del anticomunismo discreto”. En Espejos de la guerra fría: México, América Central y el Caribe, editado por Daniela Spenser. Ciudad de México: Ciesas y Porrúa, 2004, 95-117. 
Meyer, Lorenzo. La segunda muerte de la Revolución Mexicana. Ciudad de México: Cal y Arena, 1992.

Moreno-Brid, Juan Carlos y Jaime Ros Bosch. Desarrollo y crecimiento en la economía mexicana: una perspectiva histórica. Ciudad de México: Fondo de Cultura Económica, 2010.

Necoechea Gracia, Gerardo. "Interrogar la experiencia en la historia oral". Catedra No. 13, (2016): 103-120.

Orozco, Víctor. "Las luchas populares en Chihuahua". Cuadernos Políticos No. 9 (1976): 49-66.

Ramírez Salas, Mario. "La relación de la Liga Comunista 23 de Septiembre y el Partido de los Pobres en estado de Guerrero en la década de los setenta". En Movimientos armados en México, siglo XX, vol. 2, editado por Verónica Oikón y Marta Eugenia García. Zamora: El Colegio de Michoacán, Ciesas, 2008, 527-548.

Salcedo García, Carlos. "Grupo Lacandones". En La Liga Comunista 23 de septiembre, cuatro décadas a debate: historia, memoria, testimonio y literatura, editado por Rodolfo Gamiño, et al. Ciudad de México: UNAM, 2014, 183-203.

Sánchez Parra, Sergio Arturo. "La guerrilla en México: un intento de balance historiográfico”. Clío, nueva época Vol. 6 No. 35 (2006): 121-144.

Santos Valdés, José. Madera. Razón de un martirologio. Durango: Ed. Universidad Juárez del Estado de Durango, 2011.

Vargas Valdés, Jesús. Madera rebelde: movimiento agrario y guerrilla (1959-1965). Chihuahua: Nueva Vizcaya, 2015.

Vargas Valdés, Jesús. La Patria de la Juventud, los estudiantes del Politécnico en 1968. Chihuahua: Nueva Vizcaya, 2008.

Woldenberg, José. Memoria de la izquierda. Ciudad de México: Cal y Arena, 1998.

Para citar este artículo: Necoechea Gracia, Gerardo y De Los Ríos Merino, Alicia "Violencia Política y Movilización Popular: Chihuahua (México), 1972", Historia Caribe Vol. XVI No. 39 (Julio-Diciembre 2021):117-151. DOI: https://doi.org/10.15648/hc.39.2021.2962 